\title{
Residents' preferred policy actions for shrinking cities
}

\section{Maria Helena Guimarães, Luis Catela Nunes, Ana Paula Barreira \& Thomas Panagopoulos}

To cite this article: Maria Helena Guimarães, Luis Catela Nunes, Ana Paula Barreira \& Thomas Panagopoulos (2016) Residents' preferred policy actions for shrinking cities, Policy Studies, 37:3, 254-273, DOI: $10.1080 / 01442872.2016 .1146245$

To link to this article: https://doi.org/10.1080/01442872.2016.1146245

曲 Published online: 24 Feb 2016.

Submit your article to this journal $₫$

Џll Article views: 305

View Crossmark data \lceil

Citing articles: 2 View citing articles 5 


\title{
Residents' preferred policy actions for shrinking cities
}

\author{
Maria Helena Guimarães $s^{a, b}$ (D), Luis Catela Nunes ${ }^{c}$ (D), Ana Paula Barreira ${ }^{a}$ (D) and \\ Thomas Panagopoulos ${ }^{\mathrm{a}}$
}

${ }^{a}$ Research Centre for Spatial and Organizational Dynamics (CIEO), University of Algarve, Faro, Portugal;

${ }^{\mathrm{b}}$ Landscape Dynamics and Social Processes Group, Instituto de Ciências Agrárias e Ambientais Mediterrânicas (ICAAM), University of Évora, Núcleo da Mitra, Edifício Principal, Évora, Portugal; ${ }^{C}$ Nova School of Business and Economics, Universidade Nova de Lisboa, Lisboa, Portugal

\begin{abstract}
Cities facing a continued and prolonged process of population decline require innovative urban regeneration policies complementary to growth-oriented policies. Losing inhabitants involves a decrease in economic activity and social capital. Therefore citizens' participation in defining policies to cope with population decline is being increasingly advocated. This research focused on four shrinking cities of Portugal to capture residents' knowledge about the strengths and weaknesses of their city of residence as well as the policies and actions they prioritized for dealing with the population decline. The responses from 701 questionnaires show that economic revival policies as well as safety and accessibility policies were preferred. To put these policies into action, the recovery of industrial activity, the creation of business incubators, an improvement in law enforcement, and public lighting were ranked as top priorities. Rank-ordered logistic regression models were used to understand which variables influenced the residents' rankings. We found that the evaluation of the city's characteristics impact the ranking of the policies and actions. Hence, residents show a high level of coherence when engaging in a discussion at the level of policy-making. Therefore, the findings support residents' involvement in decision-making processes regarding urban regeneration in shrinking cities.
\end{abstract}

\section{ARTICLE HISTORY}

Received 17 April 2015

Revised 21 September 2015

Accepted 21 January 2016

\section{KEYWORDS}

Shrinking cities; policy and planning strategies; residents' preferences;

Portugal

\section{Introduction}

The historical evolution of human settlements has given rise to an increasing number of larger cities with surrounding urbanized areas. As life-cycle theories of urban development have shown, a city can have periods of growth, stagnation, and shrinkage (Berry 1977; van den Berg et al. 1982). Despite the multiplicity of and interconnections between the causes and consequences of such paths, one important element is the city's resilience to change, especially when shrinkage emerges as a common event (Turok and Mykhnenko 2007; Beauregard 2009). Such resilience can be assured by top-down approaches where wellestablished institutions assure that residents' well-being is maintained. However, such top-down approaches might not be appropriate when a city is in a continued and 
prolonged process of losing population (Hospers 2013, 2014). Recent experiences suggest that under the processes of population loss, top-down approaches would benefit from considering citizens' views of the phenomenon (e.g. Elzerman and Bontje 2015, for German and Dutch cases or Hollander and Németh 2011, for US cases). Nonetheless, in the majority of cases, inhabitants of cities facing population decline have been excluded from the debate (van Dalen and Henkens 2011).

Dealing with shrinkage is a complex urban governance issue that requires a psychological transformation from growth-oriented policies to those concerned with shrinkage (Hospers 2014). In this scenario, understanding residents' preferences can be decisive when developing strategies for dealing with shrinkage, because their knowledge about the attractive and unattractive features of cities is unique and irreplaceable (Brown, Perkins, and Brown 2003).

The present study was formulated based on the point of view that residents in shrinking cities need to be consulted so that the most suitable policies and actions are selected by local governments for dealing with this phenomenon. Moreover, the way in which inhabitants assess the appealing/unappealing features of their city is vital for capitalizing on a city's strengths and for overcoming its weaknesses. With this in mind, we developed a questionnaire and surveyed 701 respondents face-to-face in four cities in Portugal that are undergoing population decline: Oporto, Barreiro, Peso da Régua, and Moura. Each of these cities has a different cause of shrinkage (further detailed), which allows us to better understand the impact of a city's particular characteristics on the selection of policies and on the prioritization of subsequent actions from the viewpoint of its citizens. The use here of rank-ordered logistic regression models, a novel application in studies of city shrinkage, allows us to identify both the common and specific preferred policies and actions of the case study cities as identified by their inhabitants.

\section{Literature review}

Urban managers face two opposing realities: on the one hand, a concentration of resources and social capital in growing cities and, on the other, cities facing population decline (Martinez-Fernandez et al. 2012). The literature reveals that the growth of cities is a much more popular topic of discussion compared with shrinkage (Haase et al. 2013; Hospers 2013). Only recently, since the 1980s, has the concept of shrinkage emerged in the literature (Beauregard 2009; Hoekveld 2014), despite the study of population and economic decline appearing in urban theory a decade earlier (Haase et al. 2014).

Shrinking cities became more common after the end of the Second World War, with urban growth in many countries being replaced by stagnation and/or shrinkage (Kabisch, Haase, and Haase 2006; Rieniets 2006). Today, shrinking cities have been identified in many parts of the world and the number of such cities has increased more rapidly than the number of expanding cities (Oswalt and Rieniets 2006). As the phenomenon becomes more prevalent, the amount of literature dedicated to the identification of shrinkage, and its causes and consequences, has increased (Oswalt 2005; Haase et al. 2013). In Portugal, studies of shrinking cities are scarce but increasing (Sousa 2010; Panagopoulos and Barreira 2012; Guimarães, Barreira, and Panagopoulos 2014; Sousa and Pinho 2014; Panagopoulos, Guimarães, and Barreira 2015).

The negative consequences of urban shrinkage have prompted policy-makers in Europe to develop policy responses (Hospers 2013). The strategies range from explicitly targeted 
actions to the intensification of existing urban policies. Whereas the former approach implies an acceptance of shrinkage, the latter aims at counteracting shrinkage (Rink and Haase 2012; Hospers 2014). Hospers (2014) identifies, within European cities, four different strategies to cope with shrinkage: trivializing, countering, accepting, and utilizing. Trivializing occurs when local governments do not take the symptoms of shrinkage seriously and consequently do not take action (Hospers 2014). This strategy is common in countries (e.g. France, Spain, and Poland) where growth is the most common path of urban development (Martinez-Fernandez et al. 2012). Countering urban shrinkage includes the use of all policy measures used to promote growth; hence, the decline is considered a temporary problem (Glock and Häussermann 2004). Such pro-growth policy responses are particularly found in Central, Eastern, and Southern European cities (Bernt et al. 2012). Accepting shrinkage includes recognizing a new context and adopting policies so that its negative effects are reduced and population is stabilized (Verwest 2011). This approach has been more commonly adopted in Germany, the UK, and the Netherlands (Bernt et al. 2012). Finally, utilizing urban shrinkage starts with a positive perspective of the process and tries to take advantage of it. This approach is used mostly in Northwest Europe and is linked to the idea that a city's quality of life is not necessarily dependent on population density (Hospers 2014). In Portugal, the awareness of shrinkage is only recent; hence, most policy approaches trivialize the process or try to counter it (Panagopoulos and Barreira 2012).

Whatever policy is chosen to cope with shrinkage, international experience has shown that the particularities of the affected places need to be considered so that the goals have a chance to be achieved. Thus, 'one size fits all' policies are not recommended (Turok 2004; Haase et al. 2014). Despite this, studies addressing pull and push factors in a shrinkage environment are scarce, with the studies of Couch and Karecha (2006) and Reckien and Martinez-Fernandez (2011) being the main exceptions. The literature regards the appealing features of a city as a well-maintained physical environment, good transportation, access to health services, and high levels of environmental health (Abbott and Sapsford 2005; Bonaiuto, Fornara, and Bonnes 2006). In contrast, the fear of crime (Abbott and Sapsford 2005), the proximity of polluting industries, the concentration of unemployment (Andersen and van Kempen 2003), and perceived incivilities (Comstock et al. 2010) are viewed as unpleasant features. Knowledge of the features of a city that instil in inhabitants a sense of belonging, happiness, and residential satisfaction are crucial to understanding how social capital accumulates (Dassopoulos et al. 2012). Human factors like the promotion of social ties are determinants of civic engagement (Michener 2013; Hospers 2014). Spatial factors such as the availability of pedestrian walks, roads, and open spaces affect the quality of life (Perez et al. 2001; Grzeskowiak, Sirgy, and Widgery 2003). Functional factors related to the availability of education, policy services, public transport, and parks, as well as leisure opportunities, space for sports activities, and short distances to work have also been described as appealing features of a city (Turksever and Atalik 2001; Sirgy and Cornwell 2002). Moreover, these factors interact; for instance, the possibility of practicing outdoor sports promotes social interaction and consequently social bonds (Oh 2003; Dassopoulos et al. 2012), which increases trust relationships and decreases the feeling of insecurity (Harrison, Gemmell, and Heller 2007). In turn, the established attachment with place reduces inhabitants' desire to leave (Crowe 2007). 
Besides identifying the appealing/unappealing factors of a city, an understanding of the causes of shrinkage is essential for a proper delineation of policies and actions (Hollander 2011). In the present study, four case study cities affected by economic transformation, suburbanization, satellite effect, or harsh environmental conditions, respectively, are considered (Guimarães, Barreira, and Panagopoulos 2014). Cities that have faced severe economic transformations, mainly deindustrialization, commonly present widespread occurrences of brownfields surrounded by vacant houses (Oswalt 2005). Ways of coping with shrinkage in such cases include policies aimed towards demolition and/or reutilization, as well as the promotion of home ownership and economic regeneration (Friedrichs and Blasius 2009; Bailey and Cowling 2011). Suburbanization involves migration from the city centre to the surrounding areas as residents search for more spacious or affordable homes (Hesse 2006). Policies to reverse such migration include fiscal measures and/or revitalization of the city core (Bento, Franco, and Kaffine 2011; Kauko 2011). Cities subject to the satellite effect lose residents to nearby cities that are better equipped in services such as education and health (Merrilees, Miller, and Herington 2013), but maintain a high level of commuting with the dominant centre (Congdon and Shepherd 1986). In such a case, there is competition for residents between neighbouring cities, and the most common policies include those to attract economic activity and to increase educational opportunities (Stabler and Olfert 2002; Epple, Gordon, and Sieg 2010). Finally, harsh environmental conditions (e.g. heat waves, lack of precipitation, and frost) can also promote a prolonged decline of residents, with climate change being perhaps the most striking example (Rappaport 2007), for which actions such as greening and the use of vacant land for agricultural purposes are recommended (Comstock et al. 2010; Mallach 2010).

Because shrinkage is distinct from growth, it requires the development of targeted actions and a bottom-up approach. Hence, the starting point is an understanding of what residents' preferences are and how they prioritize available policy options. Given economic constraints, which are typically even heavier under conditions of shrinkage (Koziol 2004; Schiller and Siedentop 2006), there is a need to define what is more relevant so that existing resources can be properly channelled. The bottom-up approach is based on the premise that residents' participation in defining policies provides the best definition of policy priorities and of how and where such policies should be applied (Kantor and Savitch 2005; Wiechmann and Pallagst 2012).

Because of various reasons, cities' governments have become increasingly limited in their capacity to deal with the consequences of shrinkage, and have therefore become more dependent on citizen's willingness to help (Metzger 2000). Nevertheless, if citizens are asked to put dictated actions into practice, the success of these actions tends to be compromised. Citizens' participation at an early stage (e.g. policy definition) of decisionmaking processes allows them to start caring about the issue before cities' governments ask them to do so (Hospers 2014).

Regardless of the trajectory of a city's evolution (i.e. population growth, stability, or decline), the composition of its population may change and this can also affect citizens' policy preferences. Young couples tend to value good schools, kindergartens, and access to jobs (Montén and Thum 2010), whereas older inhabitants care more about healthcare services and safety (Abbott and Sapsford 2005). The number of years residing in a city has been found to be linked to the degree of attachment to the place (Perez et al. 2001; Brown, Perkins, and Brown 2003), which might influence citizens' willingness to 
participate in collective actions. Gender also plays an important role, as women tend to connect more to the place of residence than do men (Perez et al. 2001). Women and older residents also report higher levels of insecurity and are thus more in favour of policies to reduce crime (Smith, Torstensson, and Johansson 2001; Kamalipour, Yeganeh, and Alalhesabi 2012). Finally, higher levels of education and of income tend to be linked with residents' identification and approval of policies regarding sustainability (Vigdor 2010).

Literature in this regard is sporadic, and fails to provide a systematic understanding of resident's perception about shrinking cities so as not to be able to inform bottom-up policy approach involving residents to address shrinking cities. Therefore, we devised a methodology to consult citizens of four shrinking Portuguese cities about the push and pull factors of cities and their preferences for shrinkage policies. Our results add to knowledge about the characteristics of residents in shrinking cities, and provide valuable insights into their perceptions of the phenomenon and their preferences for policy-making. The findings give empirical support for the inclusion of residents in policy-making in urban shrinkage settings.

\section{Methods}

\section{Data collection}

A consultation process using a questionnaire survey was conducted to ascertain citizens' preferences about the policy actions that could be implemented to deal with the shrinkage of their cities, and to determine residents' perceptions of the attractiveness of their cities and how these perceptions influenced their choice of policies.

The questionnaire contained three main components: (1) collection of demographic and socio-economic data, (2) residents' evaluation of the attractiveness of each city, and (3) residents' policy and policy actions preferences. The socio-demographic component included the collection of information regarding age, gender, household size, monthly income, and other characteristics. Respondents were also questioned about their perceptions of the evolution of population (i.e. whether it was increasing, stable, or decreasing). Table 1 summarizes the demographic and socio-economic profiles of the respondents.

The attractiveness of the city was measured in two separate questions. The first question included 24 pull features that respondents were asked to rate using a Likert scale ranging from 1 (not important) to 5 (very important) according to the importance of each feature regarding the decision of respondents to live in the city. The second question included 24 push variables that respondents evaluated using the same scale but considering their relevance in a decision to possibly leave the city. The information obtained was reduced to five pull factors and four push factors using factor analysis (see details in Guimarães et al. 2015). The pull factors obtained were labelled living conditions, recreational \& environmental amenities, social ties, accessibility, and live \& work. The push factors were named lack of services, shrinking atmosphere, surrounding \& visual attributes, and working conditions.

The living conditions pull factor comprises a city's attributes that are related to the security, housing affordability, and tranquillity of the city. The recreational \& environmental amenities pull factor encapsulates the respondents' assessment of open-air areas for sport activities, footpaths, and nightlife. The social ties pull factor includes attributes 
Table 1. Descriptive statistics of the demographic and socio-economic profiles of respondents.

\begin{tabular}{|c|c|c|c|c|c|}
\hline \multicolumn{6}{|l|}{ Descriptive analysis } \\
\hline Statistics & Overall & Oporto & Barreiro & Peso da Régua & Moura \\
\hline Sample $(N)$ & 701 & 180 & 179 & 171 & 171 \\
\hline \multicolumn{6}{|l|}{ Age (Continuous variable) } \\
\hline Mean & 54 & 57 & 54 & 53 & 52 \\
\hline Maximum & 96 & 96 & 87 & 87 & 87 \\
\hline Minimum & 18 & 18 & 18 & 18 & 18 \\
\hline \multicolumn{6}{|l|}{ Gender (Nominal variable; 1 - female, 0 - male) } \\
\hline Frequency of women (\%) & 61.2 & 70.6 & 51.4 & 62.6 & 60.2 \\
\hline \multicolumn{6}{|c|}{$\begin{array}{l}\text { Education level (Ordinal variable) ( } 1 \text { - illiterate; } 2 \text { - primary school (incomplete or complete); } 3 \text { - secondary school (2 years); } \\
4 \text { - secondary school (5 years); } 5 \text { - secondary school ( } 8 \text { years); } 6 \text { - Higher education) }\end{array}$} \\
\hline Mean & 3. 34 & 3.37 & 3.55 & 3.37 & 3.07 \\
\hline Maximum & 6 & 6 & 6 & 6 & 6 \\
\hline Minimum & 1 & 1 & 1 & 1 & 1 \\
\hline \multicolumn{6}{|c|}{ Monthly household income (Ordinal variable: $1-<500 ; 2-500-1000 ; 3-1000-1500 ; 4-1500-2000 ; 5->2000)$} \\
\hline Mean & 1.93 & 1.78 & 2.25 & 1.80 & \\
\hline Maximum & 5 & 5 & 5 & 4 & 4 \\
\hline Minimum & 1 & 1 & 1 & 1 & 1 \\
\hline \multicolumn{6}{|l|}{ Household (Ordinal variable: 1 - one person to $5->4$ ) } \\
\hline Mean & 2.26 & 2.13 & 2.08 & 2.49 & 2.33 \\
\hline Maximum & 5 & 5 & 5 & 5 & 5 \\
\hline Minimum & 1 & 1 & 1 & 1 & 1 \\
\hline \multicolumn{6}{|c|}{ Era of construction (Ordinal variable; 1 - after the 1970s; 2 - before the 1970s) } \\
\hline Frequency of houses built during or after the 1970s (\%) & 52.4 & 57.8 & 45.8 & 63.7 & 58.5 \\
\hline \multicolumn{6}{|l|}{ Ownership (Nominal variable; 0 - owner; 1 - tenant) } \\
\hline Frequency of owners (\%) & 59.1 & 29.4 & 69.8 & 60.8 & 77.2 \\
\hline \multicolumn{6}{|c|}{ Years of residence (Ordinal variable; $1-<10$ years; $2-10-20$ years; $3->20$ years) } \\
\hline Mean & 2.44 & 2.42 & 2.61 & 2.28 & 2.43 \\
\hline Maximum & 3 & 3 & 3 & 3 & 3 \\
\hline Minimum & 1 & 1 & 1 & 1 & 1 \\
\hline \multicolumn{6}{|c|}{ Perception regarding population evolution (ordinal variable: 1 - diminishing; 2 - stable; 3 - growing) } \\
\hline Mean & 1.41 & 1.38 & 1.58 & 1.44 & 1.22 \\
\hline Maximum & 3 & 3 & 3 & 3 & 3 \\
\hline Minimum & 1 & 1 & 1 & 1 & 1 \\
\hline \multicolumn{6}{|c|}{ Willingness to participate in policy implementation (Nominal variable $1-$ yes; 0 - no) } \\
\hline Yes & $43 \%$ & $47 \%$ & $53 \%$ & $46 \%$ & $26 \%$ \\
\hline
\end{tabular}

such as mutual aid and trust between neighbours, community spirit, and involvement in local organizations. The accessibility pull factor integrates attributes like the availability of shopping, leisure, and nature. The life \& work pull factor includes attributes related to the proximity of home to the workplace.

The lack of services push factor includes residents' concern with shopping areas, public services, and roads. The shrinking atmosphere push factor comprises population decline, the number of elderly citizens, and vagrants in the city. The surrounding \& visual attributes push factor represents respondents' assessment of degraded and abandoned buildings, environmental quality, house size, and security. The working conditions push factor includes attributes related to the lack of job opportunities, the existence of better income elsewhere, and the distance between workplace and home.

Policy preferences were evaluated in a two-step process. In the first step, respondents were asked to rank five different policies from the most important to the least important. Subsequently, and for only the top two policies, respondents were asked to rank five different actions to be implemented for each policy selected. Table 2 lists the 5 policies and the 25 actions evaluated along with values for the average and modal rankings. 
The questionnaire was based on the literature regarding policies adopted in shrinkage environments and on a systematization of the possible pull and push attributes of a city. Further information on the specific characteristics of each city was incorporated to ensure that the questionnaire was suitable for the Portuguese context.

Data from the last 20 years indicate that 31 of the 158 cities in Portugal have lost inhabitants (Guimarães, Barreira, and Panagopoulos 2014), of which we selected 4 to investigate in the present study (as in Figure 1). Shrinkage can be driven by multiple reasons (Guimarães, Barreira, and Panagopoulos 2014; Panagopoulos, Guimarães, and Barreira 2015), with each of the cities selected representing a particular cause of shrinkage: suburbanization (Oporto), economic transformation (Barreiro), satellite effect (Peso da Régua), and environmentally driven shrinkage (Moura). In total, 701 questionnaires were conducted: 180 in Oporto, 179 in Barreiro, 171 in Peso da Régua, and 171 in Moura. The sample size ensured a maximum margin of error for the population proportion of $7.45 \%$ at the $95 \%$ confidence level. Respondents were randomly selected while respecting a predefined distribution based on household typology as revealed in census data. Questionnaires were undertaken face-to-face in all parishes of each city and during different times of the day. A pilot survey $(n=10)$ was conducted to ensure the consistency, clarity, and appropriate length of the final questionnaire.

\section{Statistical models}

To understand how respondents' differing preferences for policies (as expressed by their ranking of the alternatives) were affected by the respondents' characteristics, we used a rank-ordered logistic regression model (see Beggs, Cardell, and Hausman 1981; Chapman and Staelin 1982). This model can be generated through a random utility model where respondents rank the $m$ available alternatives according to their preferences (in the present study, $m=5$ ). In particular, it is assumed that the utility that a respondent obtains from alternative $i=1, \ldots, m$ is given by $v_{i}=\beta_{0, i}+\beta_{1, i} x_{1}+\ldots+\beta_{k, i} x_{k}+\varepsilon_{i}$, where $x_{1}, \ldots, x_{k}$ are $k$ explanatory variables capturing the respondents' characteristics, $\beta_{0, i}, \beta_{1}$, ${ }_{i}, \ldots, \beta_{k, i}$ are coefficients, and $\varepsilon_{i}$ are error terms capturing unobserved factors that also affect utility. As in the usual conditional logit model, alternative specific explanatory variables that vary across respondents can also be included in this model.

Under the assumption that the $\varepsilon_{i}$ are independent and follow an extreme value type I distribution, Luce (1959) showed that the probability, $p_{i}$, of alternative $i$ being ranked higher than the other alternatives can be expressed as $p_{i}=P\left(v_{i}>\max \left(v_{j}, j=1, \ldots, m\right.\right.$, $j \neq i))=\exp \left(v_{i}\right) / \sum_{j=1}^{m} \exp \left(v_{j}\right)$. Any ranking of the $m$ available policy alternatives can be viewed as a sequence of decisions where the policy providing the highest utility is selected first, followed by the policy with highest utility among the remaining policies, and so on. It follows that the probability of a specific ranking of policy alternatives is given by the product of $m-1$ probabilities like $p_{i}$ above.

The parameters of the model, $\beta_{0, i}, \beta_{1, i}, \ldots, \beta_{k, i}, i=1, \ldots, m$, were estimated by maximum likelihood as implemented by the rologit command in STATA (see StataCorp 2013). Because the number of parameters in this model is quite large, it becomes difficult to interpret them directly. Therefore, we examined how the predicted probabilities of each policy being ranked first were affected by each of the explanatory variables. ${ }^{1}$ 


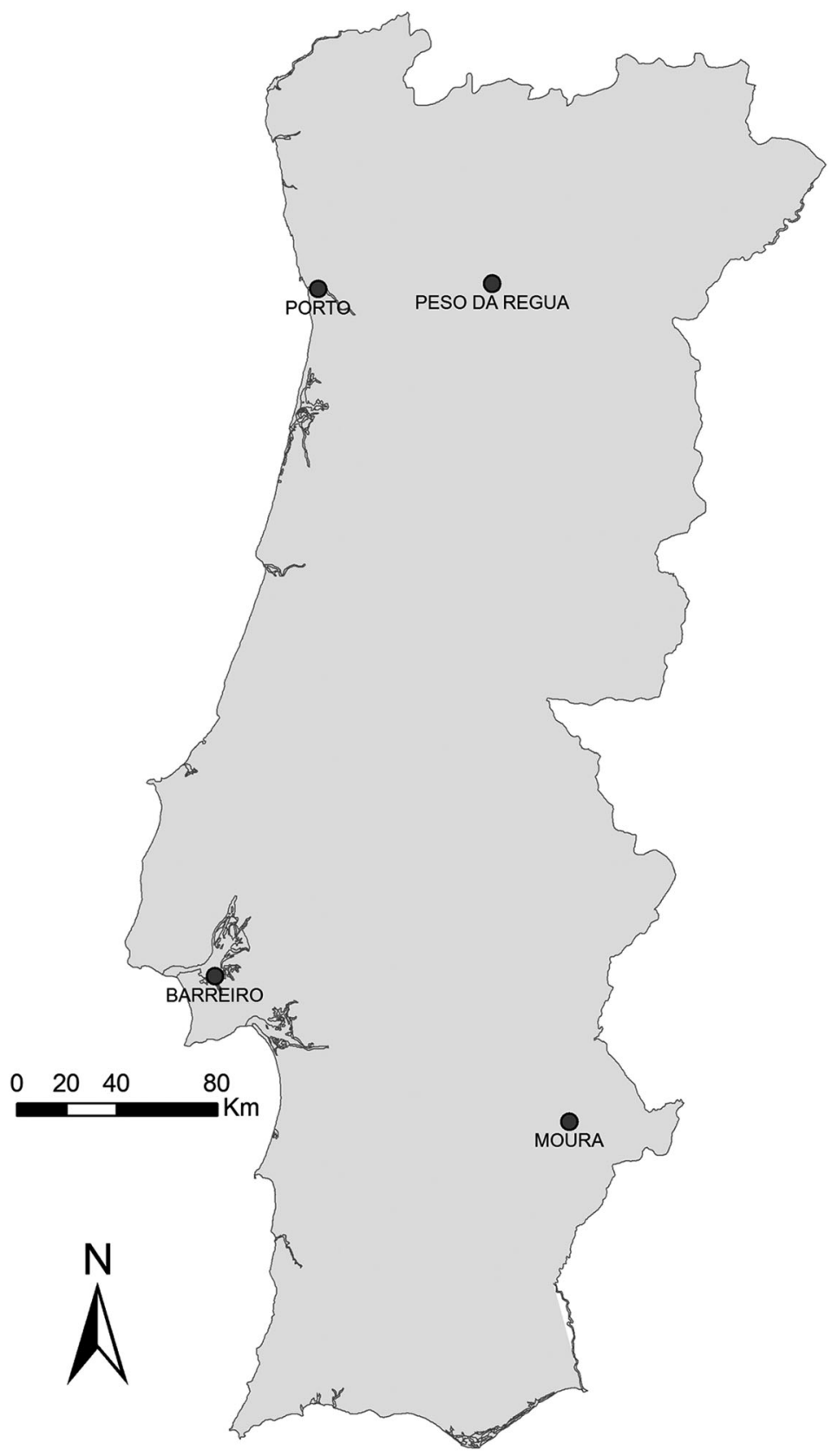

Figure 1. Locations of the four case study cities in Portugal.

\section{Results}

\section{Policies and actions: what are the priorities?}

Table 2 shows that the highest average ranking obtained was for the Economic Revival policy. For this policy, the preferred actions were the revitalization of industry, the promotion of business incubators, and the encouragement of families and young residents 
Table 2. Respondents' rankings of the policies and actions.

\begin{tabular}{|c|c|c|c|c|}
\hline \multicolumn{2}{|c|}{ Policies and actions } & Mean & Mode & $N$ \\
\hline \multicolumn{2}{|c|}{ Policy 1: Economic Revival } & 4.31 & 5 & 701 \\
\hline \multirow[t]{5}{*}{ Actions } & Development and recovery of industrial areas & 3.59 & 5 & 555 \\
\hline & Create business incubators & 3.64 & 4 & \\
\hline & Support the settlement of young residents and families & 3.78 & 3 & \\
\hline & Develop the tourism sector & 2.44 & 2 & \\
\hline & Support the settlement of residents from other countries & 1.55 & 1 & \\
\hline \multicolumn{2}{|c|}{ Policy 2: Safety \& Accessibility } & 3.21 & 4 & 701 \\
\hline \multirow[t]{5}{*}{ Actions } & Increase law enforcement & 4.42 & 5 & 347 \\
\hline & Increase public lighting & 3.97 & 4 & \\
\hline & Increase pedestrian mobility & 2.50 & 3 & \\
\hline & Increase the range of public transportation & 2.92 & 2 & \\
\hline & Increase access to surrounding cities & 1.88 & 1 & \\
\hline \multicolumn{2}{|c|}{ Policy 3: Public Services } & 2.82 & 4 & 701 \\
\hline \multirow[t]{5}{*}{ Actions } & Increase the access to and standard of health care & 4.18 & 5 & 245 \\
\hline & Increase the quantity and quality of kindergartens & 2.98 & 2 & \\
\hline & Increase the level of public services & 2.96 & 4 & \\
\hline & Increase the availability of elderly centres & 2.69 & 1 & \\
\hline & Increase the opportunity for higher education & 2.20 & 1 & \\
\hline \multicolumn{2}{|c|}{ Policy 4: Building Interventions } & 2.66 & 2 & 701 \\
\hline \multirow[t]{5}{*}{ Actions } & Rehabilitate degraded buildings & 4.42 & 5 & 185 \\
\hline & Promote the concentration of residents in the inner city & 4.09 & 4 & \\
\hline & Demolish abandoned buildings & 3.71 & 4 & \\
\hline & Reduce the cost of urban rehabilitation & 2.76 & 3 & \\
\hline & Conserve the city's heritage & 1.96 & 1 & \\
\hline \multicolumn{2}{|c|}{ Policy 5: Environmental Actions } & 2.02 & 1 & 701 \\
\hline \multirow[t]{5}{*}{ Actions } & Create more green urban areas & 3.43 & 5 & 70 \\
\hline & Develop projects for environmental improvement & 3.40 & 4 & \\
\hline & Recover environmentally degraded areas & 3.26 & 4 & \\
\hline & Create urban gardens with collective management & 2.56 & 1 & \\
\hline & Invest in renewable energy projects & 2.36 & 1 & \\
\hline
\end{tabular}

Note: All policies and actions were ranked by respondents from 1 (not important) to 5 (very important). The questionnaire asked for a ranking of the actions that corresponded only to the two most important policies ranked by each respondent. Therefore, the number of observations (last column) differs for each set of actions.

to settle. The second most valued policy was Safety \& Accessibility, for which the most important actions were improvements in law enforcement and in public lighting. Public Services was the third most important policy and the improvement of health care was the action prioritized. The fourth highest ranked policy was Building Interventions, with the corresponding preferred actions being the rehabilitation of damaged buildings, the encouragement of residents' settlement in the core of the city, and the demolition of vacant buildings. The lowest-ranked policy was Environmental Actions, with only 70 (of the 701) respondents ranking this policy as very important or important. For this policy, the creation of more green areas and the development of projects for environmental improvement were the most valued actions.

\section{What influences the ranking of policies and policy actions?}

To determine how the characteristics of the respondents influence their preferences for and ranking of the alternative policies and actions, several rank-ordered logistic regression models were estimated. The explanatory variables were the respondents' city of residence, age, gender, education level, perception of population evolution in their city, their willingness to participate in policy implementation, era of construction of their home, number of years residing in the city, and the four push and five pull factors. The income variable was 
Table 3. Summary and goodness of fit of the rank-ordered logistic regression models.

\begin{tabular}{|c|c|c|c|}
\hline Model & Policy ranking & $\begin{array}{c}\text { Economic Revival action } \\
\text { ranking }\end{array}$ & $\begin{array}{c}\text { Safety \& Accessibility action } \\
\text { ranking }\end{array}$ \\
\hline $\begin{array}{l}\text { Number of observations (equals } 5 \times \text { number } \\
\text { of respondents) }\end{array}$ & 3300 & 2775 & 1735 \\
\hline Log-likelihood & -2603.8 & -1889.7 & -1096.4 \\
\hline LR chi-square test of overall fit of the model & $\begin{array}{c}1111.8 \\
(p \text {-value }=.00)\end{array}$ & $\begin{array}{c}1504.4 \\
(p \text {-value }=.00)\end{array}$ & $\begin{array}{c}999.3 \\
(p \text {-value }=.00)\end{array}$ \\
\hline
\end{tabular}

LR Likelihood Ratio.

excluded because of too many missing values. The final selected models included only variables that were significant at the $5 \%$ level. Table 3 shows goodness-of-fit statistics for the final selected models for the ranking of the five major policies and also for the ranking of the actions within both the Economic Revival policy and the Safety \& Accessibility policy (the two most important policies identified by respondents).

The ranking of the policies was found to be influenced by the city of residence, gender, perception about population evolution, and era of construction of the dwelling (see Table 4). Although Economic Revival was by far the most important policy identified, Moura was the city where this policy showed the highest average ranking whereas Oporto registered the lowest value (see Table 4). Safety \& Accessibility was given the highest ranking value in Barreiro and the lowest in Moura. The highest ranking for the Public Services policy was found in Moura and the lowest in Oporto. The ranking of Building Interventions stands out in the case of Oporto. With the exception of Economic Revival, all policies were valued slightly higher by women than by men, with Safety \& Accessibility being the policy where this was most evident. The perception of population decline contributed to the prioritization of Economic Revival and Safety \& Accessibility. Only 7\% of the full sample considered population to be increasing; nevertheless, those respondents gave higher rankings to Public Services and Building Interventions policies. Residents living in newer houses prioritized Economic Revival and Safety \& Accessibility policies whereas those living in older dwellings rated Public Services and Building Interventions policies as being the most important.

The priority given to each policy was also influenced by the assigned importance of three of the five pull and two of the four push factors (see Table 4). The ranking value of Economic Revival was higher when the live \& work pull factor was deemed important and when low importance was attributed to the remaining two pull and two push factors (i.e. living conditions, recreational \& environmental amenities, shrinking atmosphere, and surroundings \& visual attributes). The Safety \& Accessibility policy was prioritized by respondents rating both the pull factor Living conditions and the push factor surroundings \& visual attributes as important, but was not prioritized when respondents considered live \& work to be an important pull factor. The Public Services policy was more valued when shrinking atmosphere was considered a relevant push factor. Lower importance to the Public Services policy was attributed by those respondents valuing the live \& work pull factor as well as the surrounding \& visual attributes push factor. The shrinking atmosphere and surrounding \& visual attributes push factors had a considerable influence on the prioritization of Building Interventions, with higher importance being assigned when respondents valued the surrounding \& visual attributes push factor and lower importance when the shrinking atmosphere push factor was prioritized. 
Table 4. Impact of the significant variables on the ranking of policies and actions (based on the results of rank-ordered logistic regression modelling).

\begin{tabular}{|c|c|c|c|c|c|c|c|c|c|c|c|c|c|}
\hline & \multirow[b]{2}{*}{ Variables } & \multicolumn{4}{|c|}{ Policies } & \multicolumn{4}{|c|}{ Actions for the Economic Revival Policy } & \multicolumn{4}{|c|}{ Actions for the Safety \& Accessibility Policy } \\
\hline & & $\begin{array}{c}\text { Economic } \\
\text { Revival }\end{array}$ & $\begin{array}{c}\text { Safety \& } \\
\text { Accessibility }\end{array}$ & $\begin{array}{l}\text { Public } \\
\text { Services }\end{array}$ & $\begin{array}{c}\text { Building } \\
\text { Interventions }\end{array}$ & $\begin{array}{l}\text { Develop } \\
\text { and } \\
\text { recover } \\
\text { industrial } \\
\text { areas }\end{array}$ & $\begin{array}{c}\text { Create } \\
\text { business } \\
\text { incubators }\end{array}$ & $\begin{array}{l}\text { Settlement } \\
\text { of young } \\
\text { residents } \\
\text { and families }\end{array}$ & $\begin{array}{l}\text { Develop } \\
\text { the } \\
\text { tourism } \\
\text { sector }\end{array}$ & $\begin{array}{l}\text { Increase law } \\
\text { enforcement }\end{array}$ & $\begin{array}{l}\text { Increase } \\
\text { public } \\
\text { lighting }\end{array}$ & $\begin{array}{l}\text { Improve } \\
\text { pedestrian } \\
\text { mobility }\end{array}$ & $\begin{array}{l}\text { Increase } \\
\text { the range } \\
\text { of public } \\
\text { transport }\end{array}$ \\
\hline \multirow[t]{5}{*}{$\begin{array}{l}\text { Socio- } \\
\text { Demographic }\end{array}$} & City & $\begin{array}{l}\text { Moura + } \\
\text { Oporto - }\end{array}$ & $\begin{array}{l}\text { Barreiro + } \\
\text { Moura - }\end{array}$ & $\begin{array}{l}\text { Moura } \\
+ \\
\text { Oporto } \\
-\end{array}$ & Oporto+ & Barreiro+ & Moura + & Oporto + & $\begin{array}{l}\text { Peso da } \\
\text { Régua + }\end{array}$ & Barreiro + & $\begin{array}{l}\text { Peso da } \\
\text { Régua + }\end{array}$ & 0 & Moura + \\
\hline & Age & & & & & & & & & Older + & 0 & & $\begin{array}{l}\text { Younger } \\
+\end{array}$ \\
\hline & $\begin{array}{l}\text { Gender } \\
\text { Population } \\
\text { evolution }\end{array}$ & $\begin{array}{l}\text { Male }+ \\
\text { Decreasing }\end{array}$ & $\begin{array}{l}\text { Female + } \\
+\end{array}$ & Increasing & + & & & & & & & & \\
\hline & $\begin{array}{l}\text { Educational } \\
\text { level }\end{array}$ & & & & & High level + & & Low level + & 0 & & & & \\
\hline & $\begin{array}{l}\text { Era of house } \\
\text { construction }\end{array}$ & During/after & $r$ the 1970 st & Before the & 1970s+ & $\begin{array}{l}\text { Before the } \\
1970 \text { s + }\end{array}$ & During/after & the 1970s+ & 0 & & & & \\
\hline \multirow[t]{4}{*}{ Pull factors } & $\begin{array}{l}\text { Living } \\
\text { conditions }\end{array}$ & - & + & 0 & & 0 & - & + & 0 & + & - & - & 0 \\
\hline & $\begin{array}{l}\text { Recreational \& } \\
\text { environmental }\end{array}$ & - & 0 & & & & & & & - & + & + & 0 \\
\hline & Social ties & & & & & - & + & + & 0 & & & & \\
\hline & $\begin{array}{l}\text { Accessibility } \\
\text { Live \& work }\end{array}$ & & & & & + & - & 0 & + & - & 0 & 0 & + \\
\hline \multirow[t]{4}{*}{ Push factors } & $\begin{array}{l}\text { Lack of } \\
\text { services }\end{array}$ & & & & & 0 & + & - & - & & & & \\
\hline & $\begin{array}{l}\text { Shrinking } \\
\text { atmosphere }\end{array}$ & - & 0 & + & - & - & - & + & 0 & & & & \\
\hline & $\begin{array}{l}\text { Surrounding \& } \\
\text { visual } \\
\text { attributes }\end{array}$ & - & + & - & + & - & + & 0 & - & - & + & + & - \\
\hline & $\begin{array}{l}\text { Working } \\
\text { conditions }\end{array}$ & & & & & - & + & + & - & & & & \\
\hline
\end{tabular}


Regarding the actions to put into practice within the Economic Revival policy, the results show that the city of residence, education level, and the era of housing construction influenced the ranking of actions (see Table 4). The development or recovery of industrial parks was more valued by Barreiro inhabitants, well-educated respondents, and residents living in older houses. Moura residents prioritized the creation of business incubators, which was also more valued by respondents with a higher education level. The third most important action was support for young residents and families, which received the highest ranking in Oporto and also by respondents with lower education levels. The fourth action, investment in tourism, was more valued in Peso da Régua compared with other cities.

Moreover, the ranking of Economic Revival actions was influenced by three of the five pull factors and by all push factors. The development of industry was prioritized when low importance was attributed to the social ties factor and when accessibility was valued as a pull factor. Low priority was given to the development of industry when respondents valued the shrinking atmosphere, surrounding \& visual attributes, and working conditions push factors. The creation of business incubators was valued higher by respondents placing high importance on the social ties pull factor and also when the lack of services, surrounding \& visual attributes, and working condition push factors were assigned importance. Lower priority was attributed to business incubators when the pull factors of living conditions and accessibility as well as the push factor of shrinking atmosphere were valued. Support for young residents and families was given greater importance by respondents placing high value on the pull/push factors of living conditions, social ties, working conditions, and shrinking atmosphere, whereas lower importance was attributed when the lack of services push factor was rated high. Investment in tourism was more valued by respondents identifying accessibility as an important pull factor and less importance was placed on it when the push factors of lack of services, surrounding \& visual attributes, and working conditions were identified as being influential.

The actions to put into practice under the Safety \& Accessibility policy were influenced by the city of residence and age (see Table 4), with Barreiro residents and older respondents rating law enforcement actions higher. Public lighting was more valued in Peso da Régua. An increase in the provision of public transportation was particularly prioritized by residents of Moura and younger residents. Three pull factors and one push factor were also found to influence the ranking of the Safety \& Accessibility policy actions. An increase in the level of law enforcement was assigned more importance by residents highly valuing the living conditions pull factor and by inhabitants not valuing the recreational \& environmental amenities, accessibility, and surrounding \& visual attributes factors. Public lighting was given high priority when the recreational \& environmental amenities pull factor was more valued and when the push factor surrounding \& visual attributes was important, but was given lower priority when the living conditions pull factor was valued. Better pedestrian mobility was assigned high priority when the recreational \& environmental amenities pull factor and the surrounding \& visual attributes push factor were considered important, but less so when the living conditions pull factor was highly valued. An increase in public transportation was rated higher by respondents who placed importance on the accessibility pull factor, whereas this priority was lower when the surrounding \& visual attributes push factor was important. 


\section{Discussion}

Economic Revival was the policy most preferred by the residents (see Table 2) for counteracting urban shrinkage (Glock and Häussermann 2004). However, the second most important policy was Safety \& Accessibility. Therefore, residents are also concerned about retaining good and safe living conditions, which is consistent with policy strategies in which shrinkage is accepted (Bernt et al. 2012).

\section{Shrinkage: a case-specific phenomenon}

One significant result was that the policies and actions prioritized by citizens differed between the four studied cities (see Table 2). This finding supports the argument that shrinkage requires strategies tailored to individual cases to deal with the associated issues (Turok 2004; Haase et al. 2014). Moura is an inland city (as in Figure 1) and is located in a region suffering from long-term population loss and ageing, and it also has the lowest annual income of the four studied cities. These characteristics might have contributed to the results obtained, given that Moura was the city where the Economic Revival policy received the highest ranking, as well as the action of developing business incubators. In addition, Moura residents had the highest level of support for an improvement in public transportation. Interestingly, our results diverge from policies generally expected to be prioritized under harsh climate conditions, for which actions oriented towards agriculture and the environment are predominant (Comstock et al. 2010; Mallach 2010). Peso da Régua residents assigned high importance to the policy action of developing tourism, and in fact the municipality has been investing in this direction (Guimarães, Barreira, and Panagopoulos 2014). This choice of policy action is in accordance with the identified need for cities affected by the satellite effect to attract economic activity (Stabler and Olfert 2002). The fact that Peso da Régua is located in an area of recognized natural beauty (a UNESCO World Heritage Site) supports this choice.

The causes of shrinkage are multiple, but understanding the main drivers should be a determinant of policy design (Hollander 2011). Barreiro used to be one of the main industrial centres in Iberia, and a city that steadily attracted new inhabitants. However, during deindustrialization, the city started to lose population, and in 2011 the number of inhabitants was the same as that in 1970 (Guimarães, Barreira, and Panagopoulos 2014). The importance of Barreiro's industry was recognized by residents, with the action to develop or recover industrial areas receiving the highest ranking, agreeing with previous findings (Friedrichs and Blasius 2009; Bailey and Cowling 2011). Further, the process of deindustrialization can be an abrupt phenomenon with physical impacts that can induce a sense of unsafety (Hospers 2013, 2014). Such a chain of events might also explain why Barreiro stands out regarding the prioritization of both the Safety \& Accessibility policy and the need to increase law enforcement. The example of Barreiro shows that some signs of social deprivation may exacerbate the sense of unsafety. The main cause of shrinkage in Oporto is suburbanization, which has occurred mainly because of a lack of quality housing in the city centre. As suggested in the literature (Bento, Franco, and Kaffine 2011; Kauko 2011), this issue is well perceived by residents, who gave the highest ranking to the Building Interventions policy. Accordingly, inhabitants of this city also placed importance on the policy action encouraging settlement of the young and families. 


\section{Citizens' prioritization of policies considering the pull and push factors}

Independently of the city of residence, the results obtained show that the factors influencing residents' willingness to stay in or leave the city have a strong impact on the policies and actions prioritized (see Table 4). This finding underlines the argument that residents are important stakeholders in understanding how to deal with shrinking cities because they are the best judges of the attractive/unattractive features of their cities (Kantor and Savitch 2005; Wiechmann and Pallagst 2012). Citizens show a consistent rationality that further supports their involvement in the policy-making process. The living conditions pull factor had a positive effect on the choice of the Safety \& Accessibility policy, which translated into the prioritization of the law enforcement policy action. Such results might be related to residents' willingness to improve or maintain existing living conditions, being predominantly a concern to Barreiro inhabitants. The living conditions pull factor was also important in the choice of the policy action of settling young people and families. Respondents valuing the recreational \& environmental amenities pull factor assigned lower importance to the Economic Revival policy, perhaps because of the perception that some economic activities (e.g. redevelopment of industry) may harm the environment. This factor positively influenced the choice of actions for improving the quality of the city environment and of recreational features such as public lighting and pedestrian trails. Law enforcement was less valued by respondents who assigned importance to the recreational \& environmental amenities pull factor, possibly because of the greater sense of safety that the practice of outdoor and evening activities might imply (Oh 2003; Harrison, Gemmell, and Heller 2007). Respondents valuing the life \& work pull factor also valued the Economic Revival policy, as it implies an increase in job opportunities within the city. However, when assessing policy actions, this pull factor was replaced by the social ties and accessibility factors in explaining the choices of residents. This occurred because of the two-step choice procedure: first, policies were prioritized by respondents, after which only the two most preferred policies were ranked with regard to their policy actions. From the analysis, two types of citizen were identified. Those residents that valued the social ties factor preferred the actions of developing business incubators and settling young people and families, whereas those inhabitants placing high value on the accessibility factor prioritized actions for increasing or maintaining shopping and leisure services (e.g. tourism and industrial activity). Still, respondents who valued the social ties factor did not value actions aiming to redevelop industry, probably because past deindustrialization processes have been shown to generate social problems (Andersen and van Kempen 2003), and respondents valuing the accessibility factor also valued an increase in public transportation coverage.

Respondents who valued the surrounding \& visual attributes push factor prioritized policies for decreasing the negative features of their cities, namely, Building Interventions and Safety \& Accessibility. The policy actions prioritized in the Safety and Accessibility policy were the provision of more public lighting and pedestrian walks, the same as those chosen by inhabitants who valued the recreational \& environmental amenities pull factor. Therefore, when a city's surroundings and visual attributes are a concern, residents prioritize actions to solve such problems ahead of the Economic Revival policy, despite respondents who valued surrounding \& visual attributes push factor also valuing the development of businesses incubators. The development of industrial areas 
was not valued when the surroundings of the city was considered as a push factor, because such action might contribute to the already low level of attractiveness of the city. Residents who considered the shrinking atmosphere push factor to be important preferred a reversion of the shrinkage process, as shown by the importance given to the settlement of the young and families. Those inhabitants valuing the working conditions push factor gave higher ranks to actions such as the development of business incubators and the settlement of young people and families as ways of countering the lack of employment and wellpaid jobs. Respondents who valued the lack of services push factor chose policy actions aimed at implementing business incubators, probably viewed as a requirement for triggering the attraction of other private and public services. In general terms, with the exception of Peso da Régua, actions aiming to develop tourism were not identified as being important. This might be related to the possible crowding of the city, making it more expensive and less attractive to live within the city centre.

\section{The influence of residents' socio-economic characteristics on policy preferences}

As previously explored (see Guimarães et al. 2015), some demographic and socio-economic characteristics also influence the ranking of policies and actions. Gender plays a role in the choice of policies, supporting earlier studies (Smith, Torstensson, and Johansson 2001; Kamalipour, Yeganeh, and Alalhesabi 2012). Moreover, the results show a dichotomy of preferred policies between those residents living newer houses (who perceive that their city is losing inhabitants) and those living in older houses (who are not aware of the population decline). Whereas the former group of residents prefers policies for Economic Revival and Safety \& Accessibility, the latter group prioritizes policies for Public Services and Building Interventions. There is also a dichotomy regarding the preferred actions for the policy for Safety \& Accessibility: older residents prefer more policing, whereas younger residents favour improvements in public transportation. These differences support the finding that residents' preferences for policies/actions change according to their stage of life (Abbott and Sapsford 2005; Montén and Thum 2010). Such results further support the need to understand the characteristics of city residents and to prioritize policies accordingly to fulfil their needs and encourage their continued residence in the city.

\section{Conclusions}

This investigation has provided insights for policy-making in Portuguese cities that are dealing with population decline, based on a survey of inhabitants of four shrinking cities. Economic revival was found to be the most preferred policy in the four cities studied, which may be partly due to the current economic crisis affecting Portugal. Nevertheless, the prioritizations of policies and actions differed between cities and were related to the specific characteristics of each city, including the causes of the shrinkage process. Therefore, shrinkage is clearly a case-specific issue, and consequently one that needs a tailored policy-making process.

Of the cities studied, Moura has the longest observed population decline, which explains the high priority that the city's inhabitants place on policies for counteracting shrinkage. Further, the inland location of this city also contributes to the higher importance assigned by residents to the improvement of public transportation. Residents of 
Peso da Régua, aware of the city's privileged location (within a UNESCO World Heritage Site), consider the development of tourism to be a priority. Barreiro's industrialized past has left recognizable effects on residents' perceptions of safety, which accounts for their emphasis on policies regarding safety and accessibility, specifically an increase in the level of law enforcement. Finally, Oporto's suburbanization process explains the higher priority given by its citizens to policies for building interventions, as well as the need to encourage the settlement of young people and families.

The consultation process used in this study was based on the perspective that residents of shrinking cities are the best judges of the conditions of their city, both the attractive/ favourable features and the characteristics that can lead to its abandonment. In addition, this knowledge is useful for understanding the way in which residents prioritize the policies that they believe should be implemented. By using an innovative approach to data collection and statistical analysis, our results support this hypothesis, as the policy/action rankings were shown to be influenced by residents' evaluation of the pull and push factors for each studied city. Policies focused on promoting the life quality of current residents (safety and accessibility) were preferred by those who considered living conditions to be an important pull factor. The high relevance of the recreational \& environmental amenities resulted in a lower priority being placed on policies that could impact environmental quality (economic revival) and higher priority on actions that could promote residents' safety while practicing outdoor leisure activities (public lighting and pedestrian mobility). Citizens valuing factors related to working conditions tended to prioritize actions for economic development (the creation of business incubators and settlement of young residents and families), whereas those residents who valued social ties prioritized actions for increasing economic activity, such as the creation of business incubators and settlement of young residents and families, but not industrial development. When push factors were considered, relevant policies counteracting these negative features of cities were prioritized. Building intervention and economic revival policies had high and low importance, respectively, for residents who valued the cities'surroundings and visual attributes. When a shrinking atmosphere and a lack of services were detected, residents prioritized strategies aiming to counter shrinkage, such as the creation of business incubators and the improvement of public services.

The study provides strong support for the need to involve citizens in defining the most suitable policies to deal with the processes and consequences of shrinkage. Further work should analyse the use of participatory approaches and the active involvement of citizens in detailing how to implement the actions prioritized.

\section{Note}

1. As STATA does not calculate these predicted probabilities correctly (see StataCorp 2013, 2075), they were computed separately.

\section{Disclosure statement}

No potential conflict of interest was reported by the authors. 


\section{Funding}

This work was funded by the European Regional Development Fund through the Operational Programme for Competitiveness Factors and by national funding from the Foundation for Science and Technology under the project [EXPL/ATP-EUR/0464/2013] - 'Policy guidelines for regeneration in shrinking cities'.

\section{Notes on contributors}

Maria Helena Guimarães Post- Doc Fellowship at Landscape Dynamics and Social Processes Group of Institute of Mediterranean Agricultural and Environmental Sciences (ICAAM). Finalized her Ph.D in 2013 at Azores University regarding the Sustainability of Natural Resource Management. Main research interests: Transdisciplinarity, Environmental Economics, Systems Thinking, Social-ecological systems, participatory methodologies. Ongoing projects: SharePath: Transdisciplinarity as a shared path to handle landscape management: How far can we go?

Luís Catela Nunes Associate Professor in Econometrics at Nova School of Business and Economics, Lisbon, Portugal. Ph.D. in Economics, University of Illinois at Urbana-Champaign, 1994 Research Interests: Econometrics, Time Series Analysis, Empirical Finance, Environmental Valuation.

Ana Paula Barreira Ph.D. in Economics, specialisation in Economic Policy and Public Finance, Assistant Professor in the Faculty of Economics, University of Algarve and Researcher at CIEO - Research Centre for Spatial and Organizational Dynamics. Her research is in the following themes: 1) Fiscal federalism, 2) Urban policies and strategies, and 3) Shrinkage phenomena. She was the national delegate in the Management Committee in the European project COST: "Cities regrowing smaller - Fostering knowledge on regeneration Strategies in shrinking cities across Europe." She was the researcher responsible for the project: "EXPL/ATP-EUR/0464/2013 "Policy guidelines for the regeneration in shrinking cities", granted by FCT - (Portuguese) Foundation for Science and Technology.

Thomas Panagopoulos PhD in Forestry and Natural Environment in 1995 at the Aristotle University of Thessaloniki, Greece. His main research fields are "landscape reclamation", and "sustainable development". Department Head and Landscape Architecture Master Degree Director at the University of Algarve, Portugal and at the Doctoral Program "Innovation and Land Management".

\section{ORCID}

Maria Helena Guimarães (D) http://orcid.org/0000-0002-6904-3696

Luís Catela Nunes (D) http://orcid.org/0000-0001-8115-6223

Ana Paula Barreira (i) http://orcid.org/0000-0001-5816-3361

Thomas Panagopoulos (D) http://orcid.org/0000-0002-8073-2097

\section{References}

Abbott, P., and R. Sapsford. 2005. "Living on the Margins: Older People, Place and Social Exclusion.” Policy Studies 26 (1): 29-46.

Andersen, H. T., and R. van Kempen. 2003. "New Trends in Urban Policies in Europe: Evidence from the Netherlands and Denmark." Cities 20 (2): 77-86.

Bailey, D., and K. Cowling. 2011. "Rebuilding the City: A Focus for European Industrial Policy?" Policy Studies 32 (4): 347-364.

Beauregard, R. A. 2009. "Urban Population Loss in Historical Perspective: United States, 18202000." Environment and Planning A 41 (3): 514-528.

Beggs, S., S. Cardell, and J. A. Hausman. 1981. "Assessing the Potential Demand for Electric Cars." Journal of Econometrics 17: 1-19. 
Bento, A. M., S. F. Franco, and D. Kaffine. 2011. "Welfare Effects of Anti-Sprawl Policies in the Presence of Urban Decline.” Agricultural and Resource Economics Review 40 (3): 439-450.

van den Berg, L., R. Drewett, L. H. Klaassen, A. Rossi, and C. H. T. Vijverberg. 1982. Urban Europe: A Study of Growth and Decline. Oxford: Pergamon Press.

Bernt, M., M. Cocks, C. Couch, K. Grossmann, H. Haase, and D. Rink, 2012. "Policy Response, Governance and Future Directions.” Shrink Smart Research Brief No. 2. Leipzig: Helmholtz Centre for Environmental Research.

Berry, B. J. L., ed. 1977. Urbanization and Counter Urbanization. Urban Affairs Annual Reviews Vol. II. London: Sage.

Bonaiuto, M., F. Fornara, and M. Bonnes. 2006. "Perceived Residential Environment Quality in Middle- and Low-Extension Italian Cities." Revue Européenne de Psychologie Appliquéel European Review of Applied Psychology 56: 23-34.

Brown, B., D. D. Perkins, and G. Brown. 2003. "Place Attachment in a Revitalizing Neighborhood: Individual and Block Levels of Analysis." Journal of Environmental Psychology 23 (3): 259-271.

Chapman, R. G., and R. Staelin. 1982. "Exploiting Rank Ordered Choice Set Data Within the Stochastic Utility Model." Journal of Marketing Research 19: 288-301.

Comstock, N., L. M. Dickinson, J. A. Marshall, M-J. Soobader, M. S. Turbin, M. Buchenau, and J. S. Litt. 2010. "Neighborhood Attachment and its Correlates: Exploring Neighborhood Conditions, Collective Efficacy, and Gardening." Journal of Environmental Psychology 30 (4): 435-442.

Congdon, P., and J. Shepherd. 1986. "Modelling Population Changes in Small English Urban Areas." Environment and Planning A 18 (10): 1297-1322.

Couch, C., and J. Karecha. 2006. "Controlling Urban Sprawl: Some Experience from Liverpool." Cities 23 (5): 353-363.

Crowe, J. 2007. "In Search of a Happy Medium: How the Structure of Interorganizational Networks Influence Community Economic Development Strategies." Social Networks 29 (4): 469-488.

van Dalen, H. P., and K. Henkens. 2011. "Who Fears and who Welcomes Population Decline?" Demographic Research 25 (13): 437-464.

Dassopoulos, A., C. D. Batson, R. Futrell, and B. G. Brents. 2012. "Neighborhood Connections, Physical Disorder, and Neighbourhood Satisfaction in Las Vegas." Urban Affairs Review 48 (4): 571-600.

Elzerman, K., and M. Bontje. 2015. "Urban Shrinkage in Parkstad Limburg." European Planning Studies 23 (1): 87-103.

Epple, D., B. Gordon, and H. Sieg. 2010. "Drs. Muth and Mills Meet Dr. Tiebout: Integrating Location-Specific Amenities Into Multi-Community Equilibrium Models.” Journal of Regional Science 50 (1): 381-400.

Friedrichs, J., and J. Blasius. 2009. “Attitudes of Owners and Renters in Deprived Neighbourhood.” European Journal of Housing Policy 9 (4): 435-455.

Glock, B., and H. Häussermann. 2004. "New Trends in Urban Development and Public Policy in Eastern Germany: Dealing with the Vacant Housing Problem at the Local Level." International Journal of Urban and Regional Research 28 (4): 919-929.

Grzeskowiak, S., M. J. Sirgy, and R. Widgery. 2003. "Residents' Satisfaction with Community Services: Predictors and Outcomes." The Journal of Regional Analysis and Policy 33 (2): 1-33.

Guimarães, M. H., A. P. Barreira, and T. Panagopoulos. 2014. "Shrinking Cities in Portugal Where and Why." Proceedings of the 20th APDR congress, 706-721, Évora, Portugal, July 10-11. ISBN 9789898780010.

Guimarães, M. H., L. C. Nunes, A. P. Barreira, and T. Panagapoulos. 2015. "What Makes People Stay or Leave in Shrinking Cities? - An Empirical Study in Portugal.” Working Paper no 392, New University of Lisbon.

Haase, A., M. Bernt, K. Grobmann, V. Mykhnenko, and D. Rink. 2013. "Varieties of Shrinkage in European Cities." European Urban and Regional Studies 46: 1-17.

Haase, A., D. Rink, K. Grossmann, M. Bernt, and V. Mykhnenko. 2014. "Conceptualizing Urban Shrinkage." Environment and Planning A 46 (7): 1519-1534. 
Harrison, R., I. Gemmell, and R. Heller. 2007. "The Population Effect of Crime and Neighbourhood on Physical Activity: An Analysis of 15,461 Adults." Journal of Epidemiology \& Community Health 61 (1): 34-39.

Hesse, M. 2006. "Suburbanization." In Atlas of Shrinking Cities, edited by P. Oswalt, 96-07. Ostfildern: Hatje Cantz.

Hoekveld, J. J. 2014. "Understanding Spatial Differentiation in Urban Decline Levels." European Planning Studies 22 (2): 362-382.

Hollander, J. B. 2011. "Can a City Successfully Shrink? Evidence from Survey Data on Neighborhood Quality.” Urban Affairs Review 47 (1): 129-141.

Hollander, J. B., and J. Németh. 2011. "The Bounds of Smart Decline: A Foundational Theory for Planning Shrinking Cities.” Housing Policy Debate 21 (3): 349-367.

Hospers, G-J. 2013. "Coping with Shrinkage in Europe's Cities and Towns." Urban Design International 18 (1): 78-89.

Hospers, G-J. 2014. "Policy Responses to Urban Shrinkage: From Growth Thinking to Civic Engagement.” European Planning Studies 22 (7): 1507-1523.

Kabisch, S., A. Haase, and D. Haase. 2006. "Beyond Growth - Urban Development in Shrinking Cities as a Challenge for Modelling Approaches" 3rd Biennial meeting of the International Environmental Modelling and Software Society, Vermont.

Kamalipour, H., A. J. Yeganeh, and M. Alalhesabi. 2012. "Predictors of Place Attachment in Urban Residential Environments: A Residential Complex Case Study.” Procedia - Social and Behavioral Sciences 35: 459-467.

Kantor, P., and H. V. Savitch. 2005. "How to Study Comparative Urban Development Politics: A Research Note." International Journal of Urban and Regional Research 29 (1): 135-151.

Kauko, T. 2011. "An Evaluation of the Sustainability of Inner City Residential Projects." Housing, Theory and Society 28 (2): 144-165.

Koziol, M. 2004. "The Consequences of Demographic Change for Municipal Infrastructure." German Journal of Urban Studies 43 (1): 1-13.

Luce, R. D. 1959. Individual Choice Behavior: A Theoretical Analysis. New York: John Wiley \& Sons. Mallach, A. 2010. Facing the Urban Challenge: The Federal Government and America's Older Distressed Cities. Washington, DC: The Brookings Institution, Metropolitan Policy Program.

Martinez-Fernandez, C., I. Audirac, S. Fol, and E. Cunningham-Sabot. 2012. "Shrinking Cities: Challenges of Globalization.” International Journal of Urban and Regional Research 36 (2): 213-225.

Merrilees, B., D. Miller, and C. Herington. 2013. "City Branding: A Facilitating Framework for Stressed Satellite Cities.” Journal of Business Research 66 (1): 37-44.

Metzger, J. T. 2000. "Planned Abandonment. The Neighbourhood Life-Cycle Theory and National Urban Policy." Housing Policy Debate 11 (1): 7-40.

Michener, J. 2013. "Neighbourhood Disorder and Local Participation: Examining the Political Relevance of 'Broken Windows'.” Political Behavior 35: 777-806.

Montén, A., and M. Thum. 2010. "Ageing Municipalities, Gerontocracy and Fiscal Competition.” European Journal of Political Economy 26 (2): 235-247.

Oh, J. 2003. "Social Bonds and the Migration Intentions of Elderly and Urban Residents: The Mediating Effect of Residential Satisfaction." Population Research and Policy Review 22 (2): 127-146.

Oswalt, P., ed. 2005. Shrinking Cities: International Research. Vol. 1. Ostfildern: Hatje Cantz.

Oswalt, P., and T. Rieniets, eds. 2006. Atlas of Shrinking Cities. Ostfildern: Hatje Cantz.

Panagopoulos, T., and A. P. Barreira. 2012. "Shrinkage Perceptions and Smart Growth Strategies for the Municipalities of Portugal.” Built Environment 38 (2): 276-292.

Panagopoulos, T., M. H. Guimarães, and A. P. Barreira. 2015. "Influences on Citizens' Policy Preferences for Shrinking Cities: A Case Study of Four Portuguese Cities.” Regional Studies, Regional Science 2 (1): 141-170.

Perez, F. R., G. Fernandez-Mayoralas, F. E. P. Rivera, and J. M. R. Abuin. 2001. “Ageing in Place: Predictors of the Residential Satisfaction of Elderly." Social Indicators Research 54 (2): 173-208. 
Rappaport, J. 2007. “Moving to Nice Weather." Regional Science and Urban Economics 37 (3): 375398.

Reckien, D., and C. Martinez-Fernandez. 2011. "Why do Cities Shrink?” European Planning Studies 19 (8): 1375-1397.

Rieniets, T. 2006. "Urban shrinkage." In Atlas of Shrinking Cities, edited by P. Oswalt and T. Rieniets, 30-31. Ostfildern: Hatje Cantz.

Rink, D., and A. Haase. 2012. "Protest, Participation, Empowerment: Civic Engagement in Shrinking Cities in Europe: The Example of Housing and Neighbourhood Development." In Front-runners in Innovative Citizen Participation - Shrinking Areas, edited by A. Haase, G-J. Hospers, S. Pekelsma, and D. Rink, 29-39. European Urban Knowledge Network.

Schiller, G., and S. Siedentop. 2006. "Preserving Cost-Efficient Infrastructure Supply in Shrinking Cities." Working Paper, Institute of Regional Development Planning, University of Stuttgart.

Sirgy, M. J., and T. Cornwell. 2002. "How Neighborhood Features Affect Quality of Life." Social Indicators Research 59 (1): 79-114.

Smith, W. R., M. Torstensson, and K. Johansson. 2001. "Perceived Risk and Fear of Crime: Gender Differences in Contextual Sensitivity." International Review of Victimology 8 (2): 159-181.

Sousa, S. A. 2010. "Planning for Shrinking Cities in Portugal." Submitted to the Faculty of Engineering of the University of Oporto, in Partial Fulfilment of the Requirements for the Degree of Doctor in Civil Engineering.

Sousa, S., and P. Pinho. 2014. "Shrinkage in Portuguese National Policy and Regional Spatial Plans: Concern or Unspoken Word?” Journal of Spatial and Organizational Dynamics 2 (4): 260-275. http://www.cieo.pt/discussion_papers_editions.php.

Stabler, J. C., and M. R. Olfert. 2002. Saskatchewan.S Communities in the 21st Century. From Places to Regions. Regina: Canadian Plains Research Center.

StataCorp. 2013. Stata 13 Base Reference Manual. College Station, TX: Stata Press.

Turksever, A. N., and G. Atalik. 2001. "Possibilities and Limitations for the Measurement of the Quality of Life in Urban Areas.” Social Indicators Research 53 (2): 163-187.

Turok, I. 2004. "Cities, Regions and Competitiveness." Regional Studies 38 (9): 1069-1083.

Turok, I., and V. Mykhnenko. 2007. “The Trajectories of European Cities, 1960-2005." Cities 24 (3): 165-182.

Verwest, F. 2011. Demographic Decline and Local Government Strategies: A Study of Policy Change in the Netherlands. Delft: Eburon.

Vigdor, J. L. 2010. "Is Urban Decay Bad? Is Urban Revitalization Bad Too?” Journal of Urban Economics 68 (3): 277-289.

Wiechmann, T., and K. M. Pallagst. 2012. "Urban Shrinkage in Germany and the USA: A Comparison of Transformation Patterns and Local Strategies." International Journal of Urban and Regional Research 36 (2): 261-280. 